University of Nebraska - Lincoln

DigitalCommons@University of Nebraska - Lincoln

2009

\title{
Probabilistic movement model with emigration simulates movements of deer in Nebraska, 1990-2006
}

\author{
Charles J. Frost \\ University of Nebraska-Lincoln \\ Scott E. Hygnstrom \\ University of Nebraska-Lincoln, shygnstrom1@unl.edu \\ Andrew J. Tyre \\ University of Nebraska-Lincoln, atyre2@unl.edu \\ Kent M. Eskridge \\ University of Nebraska-Lincoln, keskridge1@unl.edu \\ David M. Baasch \\ University of Nebraska-Lincoln, baaschd2@gmail.com
}

See next page for additional authors

Follow this and additional works at: https://digitalcommons.unl.edu/natrespapers

Part of the Natural Resources and Conservation Commons

Frost, Charles J.; Hygnstrom, Scott E.; Tyre, Andrew J.; Eskridge, Kent M.; Baasch, David M.; Boner, Justin R.; Clements, Gregory M.; Gilsdorf, Jason M.; Kinsell, Travis C.; and Vercauteren, Kurt C., "Probabilistic movement model with emigration simulates movements of deer in Nebraska, 1990-2006" (2009). Papers in Natural Resources. 171.

https://digitalcommons.unl.edu/natrespapers/171

This Article is brought to you for free and open access by the Natural Resources, School of at DigitalCommons@University of Nebraska - Lincoln. It has been accepted for inclusion in Papers in Natural Resources by an authorized administrator of DigitalCommons@University of Nebraska - Lincoln. 


\section{Authors}

Charles J. Frost, Scott E. Hygnstrom, Andrew J. Tyre, Kent M. Eskridge, David M. Baasch, Justin R. Boner, Gregory M. Clements, Jason M. Gilsdorf, Travis C. Kinsell, and Kurt C. Vercauteren 


\title{
Probabilistic movement model with emigration simulates movements of deer in Nebraska, 1990-2006
}

\author{
Charles J. Frost ${ }^{\mathrm{a}, *}$, Scott E. Hygnstrom ${ }^{\mathrm{b}}$, Andrew J. Tyre ${ }^{\mathrm{b}}$, Kent M. Eskridge ${ }^{\mathrm{c}}$, David M. Baasch ${ }^{\mathrm{a}}$, \\ Justin R. Boner ${ }^{\mathrm{a}}$, Gregory M. Clements ${ }^{\mathrm{a}}$, Jason M. Gilsdorf ${ }^{\mathrm{b}, 1}$, Travis C. Kinsell $^{\mathrm{a}}$, Kurt C. Vercauteren ${ }^{\mathrm{d}}$ \\ a School of Natural Resources, University of Nebraska-Lincoln, Lincoln, NE 68583-0962, USA \\ b School of Natural Resources, University of Nebraska-Lincoln, Lincoln, NE 68583-0974, USA

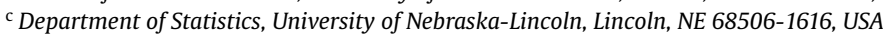 \\ d USDA, APHIS, WS, National Wildlife Research Center, 4101 LaPorte Avenue, Fort Collins, CO 80521-2154, USA
}

\section{A R T I C L E I N F O}

\section{Article history:}

Received 3 August 2008

Received in revised form 10 June 2009

Accepted 12 June 2009

Available online 3 August 2009

\section{Keywords:}

Dispersal

Individual-based model

Migration

Movement

Mule deer

Nebraska

Odocoileus hemionus

Odocoileus virginianus

White-tailed deer

\begin{abstract}
A B S T R A C T
Movements of deer can affect population dynamics, spatial redistribution, and transmission and spread of diseases. Our goal was to model the movement of deer in Nebraska in an attempt to predict the potential for spread of chronic wasting disease (CWD) into eastern Nebraska. We collared and radio-tracked $>600$ white-tailed deer (Odocoileus virginianus) and mule deer (Odocoileus hemionus) in Nebraska during 1990-2006. We observed large displacements (>10 km) for both species and sexes of deer, including migrations up to $100 \mathrm{~km}$ and dispersals up to $50 \mathrm{~km}$. Average distance traveled between successive daily locations was $166 \mathrm{~m}$ for male and 173 for female deer in eastern Nebraska, and $427 \mathrm{~m}$ for male and 459 for female deer in western Nebraska. Average daily displacement from initial capture point was $10 \mathrm{~m}$ for male and $14 \mathrm{~m}$ for female deer in eastern Nebraska, and $27 \mathrm{~m}$ for male and $28 \mathrm{~m}$ for female deer in western Nebraska. We used these data on naturally occurring movements to create and test 6 individualbased models of movement for white-tailed deer and mule deer in Nebraska, including models that incorporated sampling from empirical distributions of movement lengths and turn angles (DIST), correlated random walks (CRW), home point fidelity (FOCUS), shifting home point (SHIFT), probabilistic movement acceptance (MOVE), and probabilistic movement with emigration (MOVEwEMI). We created models in sequence in an attempt to account for the shortcomings of the previous model(s). We used the Kolmogrov-Smirnov goodness-of-fit test to verify improvement of simulated annual displacement distributions to empirical displacement distributions. The best-fit model $(D=0.07$ and 0.08 for eastern and western Nebraska, respectively) included a probabilistic movement chance with emigration (MOVEwEMI) and resulted in an optimal daily movement length of $350 \mathrm{~m}$ (maximum daily movement length of $2800 \mathrm{~m}$ for emigrators) for eastern Nebraska and $370 \mathrm{~m}$ (maximum of $2960 \mathrm{~m}$ ) for western Nebraska. The proportion of deer that moved as emigrators was 0.10 and 0.13 for eastern and western Nebraska, respectively. We propose that the observed spread of CWD may be driven by large movements of a small proportion of deer that help to establish a low prevalence of the disease in areas east of the current endemic area. Our movement models will be used in a larger individual-based simulation of movement, survival, and transmission of CWD to help determine future surveillance and management actions.
\end{abstract}

(C) 2009 Elsevier B.V. All rights reserved.

\section{Introduction}

It is inherently difficult to quantify individual movement processes in ecology. Relationships among animals and habitats are complex, collecting necessary data is difficult, and results are

\footnotetext{
* Corresponding author at: 244 Hardin Hall, University of Nebraska-Lincoln, Lincoln, NE 68583-0962, USA. Tel.: +1 402472 0508; fax: +1 4024722946.

E-mail address: charles.frost@huskers.unl.edu (C.J. Frost).

${ }^{1}$ Present address: USDA, APHIS, WS, 9001 E. Frontage Rd. Ste. A, Palmer, AK 99645 , USA.
}

often too situational to provide large-scale insights (Grimm and Railsback, 2005). Population size is a result of births, deaths, and spatial redistribution by individual movements (immigration and emigration). Ecologists can pick from a variety of methods to describe fecundity and survival relationships, but literature on methodology for modeling movements is less prevalent (Turchin, 1998).

Movements of white-tailed deer (Odocoileus virginianus) and mule deer (Odocoileus hemionus) outside of established home ranges are generally categorized as either dispersal or migration (e.g., Brinkman et al., 2005; Oyer et al., 2007). Dispersal is commonly defined as a permanent movement from natal range to

0304-3800/\$ - see front matter (c) 2009 Elsevier B.V. All rights reserved. 
adult range (Kenward et al., 2001). Dispersal rates and distances are highly variable among species, sex, age, and location (e.g., Brinkman et al., 2005; Long et al., 2005; Nixon et al., 2007), and can be influenced by a variety of factors, including the composition and quality of habitat (Long et al., 2005) and social pressures of sexual competition (Kammermeyer and Marchinton, 1976), maternal aggression (Holzenbein and Marchinton, 1992), and breeding behavior (Rosenberry et al., 2001). Migration is movement between seasonal ranges, and is well documented for white-tailed deer (e.g., Nelson, 1998; Holzenbein and Marchinton, 1992; Nelson et al., 2004) and mule deer (e.g., Thomas and Irby, 1990; Mackie et al., 1998; Sawyer et al., 2005). Both dispersal and migration can have significant effects on population size, gene flow, and transmission and spread of disease (Long et al., 2005; Oyer et al., 2007). Studies of dispersal or migration of deer have generally provided rates and average distance of movements, but normally do not attempt to project annual spatial redistribution of populations. We were unable to find similar attempts at individual-based modeling of spatial redistribution of populations of white-tailed deer or mule deer in scientific literature.

Our goal was to create a rule set that recreates the observed distributions of movements of deer in eastern and western Nebraska and use them in an individual-based simulation model of the spread of chronic wasting disease (CWD) in the state. Chronic wasting disease is a fatal, naturally occurring transmissible spongiform encephalopathy (TSE) endemic to western Nebraska that affects free-ranging and captive deer (Odocoileus spp.), elk (Cervus elaphus) (Spraker et al., 1997; Miller et al., 2000), and moose (Alces alces) (Kreeger et al., 2006). The disease was first found in free-ranging deer in Nebraska in the western Panhandle in 2000. Since then, CWD has become more prevalent and begun to spread eastward into areas with higher densities of deer. Movements of individual animals could introduce the disease to unexposed areas (Oyer et al., 2007), and a reliable model could be useful for predicting rates and pathways of spread, as well as aid in the development of management strategies.

\section{Study area}

DeSoto National Wildlife Refuge (DNWR) was located adjacent to the Missouri River on the Nebraska-Iowa border $30 \mathrm{~km}$ north of Omaha, Nebraska. The $32-\mathrm{km}^{2}$ refuge primarily consisted of forest (40\%), seasonal cropland (25\%), and grassland (20\%). Historically, crops included corn, soybeans, sorghum, and a clover/alfalfa mix. Food plots were often left standing throughout the winter to benefit wildlife. Major state and federal highways parallel the river on both sides and a major state highway runs east-west just north of the refuge.

We collared and ear-tagged 464 white-tailed deer on DNWR during 1990-2006. Resultant data were used to develop refuge-specific hunting seasons and harvest recommendations. Since 2005, DNWR has hosted 2-day hunts (either-sex muzzleloader in December, antlerless-only muzzleloader in early October, and antlerless-only rifle in late October and January) that resulted in the harvest of 600-700 white-tailed deer per year. In addition, archery hunting was allowed around the perimeter of DNWR and resulted in the harvest of about 50 deer annually. Helicopter counts at DNWR in January were $29.3,24.9$, and $22.7 \mathrm{deer} / \mathrm{km}^{2}$ in 2005, 2006, and 2007 , respectively.

Morrill County, Nebraska (MC) was located in the Panhandle of western Nebraska approximately $72 \mathrm{~km}$ east and north of Wyoming and Colorado, respectively. The $3688-\mathrm{km}^{2}$ county contained a population of 5423 people, most of which resided in the small towns of Bayard, Bridgeport, Broadwater, and Angora (U.S. Census Bureau, 2000). The North Platte River ran diagonally through the middle of Morrill County and was bounded by stands of cottonwood (Populous deltoids) and Russian olive (Eloigns angustifolia). The land to the north and south was mainly used as pasture for cattle (70\%) or irrigated cropland (25\%). Primary crops in the region were corn, soybeans, alfalfa, and sugar beets. Two major state highways converge near the center of the county, one ran parallel to the river and the other perpendicular.

We collared and ear-tagged 150 deer in MC from 2004 to 2006. Morrill County hosted 3 separate hunting seasons for deer: archery (115 days between mid-September and December), firearm (9 days in mid-November), and muzzleloader (31 days in December). All 3 hunting seasons allowed the harvest of either sex and species of deer. Total harvest in MC during 2004-2006 was approximately 1500 deer. Mule deer and white-tailed deer were observed with relatively the same frequency in MC, and density estimates by ground surveys (0.5-1.5 deer $\left./ \mathrm{km}^{2}\right)$ are much lower than in eastern Nebraska.

\section{Methods}

We captured deer using netted-cage traps, helicopter netgunning, rocket nets, and remote chemical immobilization and equipped them with radio-collars with 4-6-h mortality switches (Advanced Telemetry Systems, Isanti, MN, USA) or ear tags. We identified age class of deer at capture as fawn (6-12 months), yearling (13-24 months), or adult (>24 months). We attempted to keep species, sex, and age classes of collared deer approximately equal in MC, but previous research efforts in DNWR resulted in an approximately 2:1 ratio of female to male deer. Deer were located on average 3 times per week at all times of the day and night with vehicle-mounted telemetry systems that included electronic compasses and onboard computers (Gilsdorf et al., 2008). We collected 21051 locations of white-tailed deer in the vicinity of DNWR during 1991-2006 and 10911 locations of mule deer and white-tailed deer in MC during 2004-2006 by direct observation and radio-telemetry. About $25 \%$ of our locations were obtained by direct observation. All methods associated with live deer were approved by the University of Nebraska-Lincoln Institutional Animal Care and Use Committee (IACUC \#06-07-030C).

We calculated characteristics of movements between consecutive locations, including: displacement from initial capture point and last known location, turn angle, cosine and sine of turn angle, bearing of turn, directionality of turn (left or right), and daily displacement rate using Excel (Microsoft Corp., Redondo, CA, USA). We defined average daily movement (ADM) as the mean distance traveled between successive locations each day and average daily displacement (ADD) as the mean distance from initial point of capture each day. We kept movement independent of underlying habitat types to allow movement rules to emerge from empirical observations, which allowed us to use the same model for deer in both eastern and western Nebraska. We were not concerned with resource use or habitat selection, only annual spatial redistribution of the population. We defined redistribution as the probability of an individual reaching a given annual displacement. Therefore, the spatial component of our models emerged from differences in optimal parameter sets.

Average displacements were significantly different for study area (eastern or western Nebraska, $t$-test, $p=0.019$ ), but were not significantly different among species $(p=0.533$ between whitetailed deer and mule deer in western Nebraska), sex ( $p=0.436$ for eastern Nebraska, $p=0.311$ for western Nebraska), or age classes (yearling and adult, $p=0.497$ for eastern Nebraska and 0.387 for western Nebraska). Therefore, we created separate rule sets for the eastern and western populations and simulated deer movement using $\mathrm{C}++$. We established a population of 10000 deer that were 
Table 1

Six models of movement of deer in Nebraska, 1990-2006, including number $(k)$ and list of free parameters, as well as range of values sampled for simulation.

\begin{tabular}{|c|c|c|c|}
\hline Model & $k$ & List & Range \\
\hline Recreate distributions (DIST) & 0 & $\mathrm{~N} / \mathrm{A}^{\mathrm{a}}$ & $\mathrm{N} / \mathrm{A}$ \\
\hline Correlated random walks (CRW) & 0 & $N / A^{a}$ & $\mathrm{~N} / \mathrm{A}$ \\
\hline Home point focus (FOCUS) & 3 & $\begin{array}{l}\text { Movement length } \\
\text { Variance slope } \\
\text { Variance intercept }\end{array}$ & $\begin{array}{l}{[250,500]} \\
(0,4] \\
{[0,10]}\end{array}$ \\
\hline Shifting home point (SHIFT) & 4 & $\begin{array}{l}\text { Movement length } \\
\text { Variance slope } \\
\text { Variance intercept } \\
\text { Probability of relocation }\end{array}$ & $\begin{array}{l}{[250,500]} \\
(0,4] \\
{[0,10]} \\
(0,0.05]\end{array}$ \\
\hline Probabilistic movement (MOVE) & 2 & $\begin{array}{l}\text { Movement length } \\
\text { Movement acceptance }\end{array}$ & $\begin{array}{l}{[250,500]} \\
{[0.002,0.008]}\end{array}$ \\
\hline Probabilistic movement with emigration (MOVEwEMI) & 4 & $\begin{array}{l}\text { Movement length } \\
\text { Movement acceptance } \\
\text { Proportion of emigrators } \\
\text { Emigrator maximum movement length }\end{array}$ & $\begin{array}{l}{[250,500]} \\
{[0.002,0.008]} \\
{[0,0.25]} \\
{[250,4750]}\end{array}$ \\
\hline
\end{tabular}

a The models DIST and CRW were based on empirical movement distributions and characteristics, and therefore had no free parameters.

characterized by a log of simulated spatial locations. We initiated a deer at random $X$ and $Y$ coordinates, determined distance traveled and bearing, then updated the current location of each deer. Deer moved around a continuous landscape with no boundaries to movement in place. We simulated 365 consecutive daily movements and recorded annual displacement for each individual.

\subsection{Model descriptions}

We designed 6 models to recreate observed redistribution patterns (Table 1). We attempted to use the information gained from the shortcomings of each comparison to design the subsequent rule set. Subsequent models included:

1. Recreate distributions (DIST): We sampled the set of observed movement lengths and turn angles between consecutive locations for all deer by study area. An individual movement consisted of a movement length drawn randomly from the set of observed movement lengths in a direction dictated by a turn angle drawn in the same manner.

2. Correlated random walks (CRW): Correlated random walks follow:

$E\left(R_{n}^{2}\right)=n\left(\frac{m_{2}-c \cdot m_{2}+2 c \cdot m_{1}^{2}}{1-c}\right)$

where $E\left(R_{n}^{2}\right)=$ expected squared displacement after $n$ movements; expected squared displacement after $n$ movements; $m_{1}=$ average movement length, $m_{2}=$ average squared movement length, $c=$ average cosine of turn angles, and $n=$ number of movements.

We constructed CRW paths based on the observed characteristics of movement lengths and turn angles (Table 2). We used observed numbers of movements recorded in a year (range of 40-244) for values of $n$ to simulate annual displacement.

\section{Table 2}

Average movement length $\left(m_{1}\right)$ in $\mathrm{m}$, average squared movement length $\left(m_{2}\right)$ in $\mathrm{m}^{2}$, and average cosine of turn angle $(c)$ between consecutive locations for white-tailed deer in eastern Nebraska and mule deer and whitetailed deer in western Nebraska, 2004-2006.

\begin{tabular}{lll}
\hline & Eastern & Western \\
\hline$m_{1}$ & 171.1 & 441.8 \\
$m_{2}$ & 80684 & 226971 \\
$c$ & -0.322 & -0.341 \\
\hline
\end{tabular}

3. Home point focus (FOCUS): Movement lengths were held constant for all deer in each simulation, while we drew samples for turn angles from a normal distribution with a mean equal to the turn angle required to return the deer to its initial point (assumed to be the center of its home range). We designed variance to fluctuate as a function of displacement, increasing as an individual came closer to its starting point:

$s^{2}=(a d+b)^{-1}$

where $a$ =variable slope parameter, $d$ = distance from origin, and $b=$ variable intercept parameter.

We sampled values of $a$ and $b$ from uniform distributions (Table 1) using a Latin hypercube (LH; McKay et al., 1979). As $d$ increased, $s^{2}$ decreased, which resulted in a higher probability of a deer turning toward the center of its simulated home range. Variance was high when a deer was nearer to its home range center, which resulted in turns that would take the individual farther away from its initial point.

4. Shifting home point focus (SHIFT): Methods were similar to FOCUS above, only an additional parameter was included that allowed individuals to relocate the corresponding home range center with a given probability to account for observed deer that had multiple centers of activity or seasonal home ranges. We used LH to sample values of $a, b$, and the probability of relocation (Table 1).

5. Probabilistic movement (MOVE): Movement lengths were held constant over all deer for each simulation and turn angles were uniformly random for each move over $\left[0^{\circ}, 360^{\circ}\right)$. A movement was first "proposed" to a deer and always accepted if the proposed displacement $\left(d_{2}\right)$ from individual home point (initial location) was less than the current displacement $\left(d_{1}\right)$. If $d_{1}<d_{2}$, the move was accepted with probability:

$p=e^{-r\left(d_{2}-d_{1}\right)}$

where $r$ was a free parameter sampled using LH for each simulation (Table 1).

6. Probabilistic movement with emigration (MOVEwEMI): Methods were similar to MOVE above, only a percentage of deer (emigrators), based initially on observation but fit as a free parameter, were allowed to move with random turn angles and random movement lengths between 0 and $l_{\max }$. We attempted to account for what appeared to be random movement by deer in every species, sex, and age class, while still capturing the predominant trend of small annual displacement $(<500 \mathrm{~m})$. 


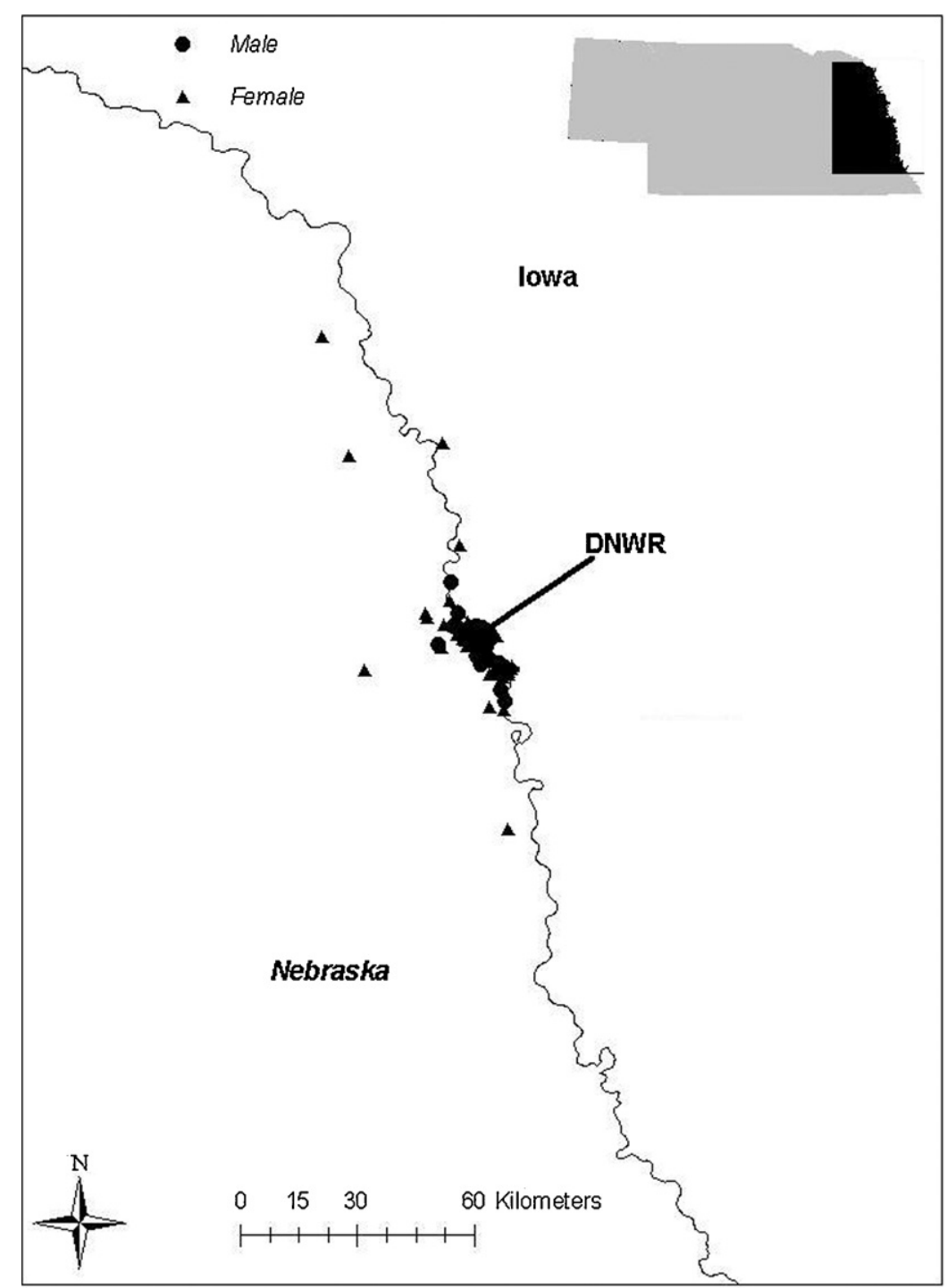

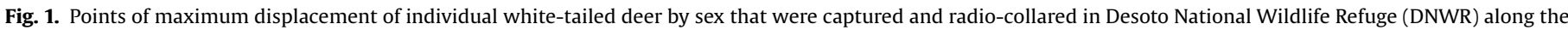
Missouri River in eastern Nebraska, 1990-2006.

We compared annual simulation displacement cumulative distribution functions (CDF) to empirical CDFs in $\mathrm{R}$ ( $\mathrm{R}$ Development Core Team, 2005). We used the Kolmogrov-Smirnov goodness-offit (KS) test to determine fit because it is free of any assumptions of underlying distributions in the data. The test statistic $(D)$ refers to the maximum vertical distance between 2 CDF curves. $p$-Values were not available since ties generated by simulation violate the assumption of a continuous distribution. The $D$ statistic was used to compare models and verify improvement, rather than accepting or rejecting hypotheses (Turchin, 1998). We minimized $D$ over the parameters involved in each rule set for each study site. The CDF curves for each simulation were compared to empirical patterns before a new rule set was created.

\section{Results}

We observed a large degree of individual variation in movement between deer of both species and sexes. The largest 6 displacements in eastern Nebraska were made by female white-tailed deer, with 5 of the 6 made along the Missouri River (Fig. 1). Four adult female mule deer in western Nebraska, out of a herd of $>100$ mule deer, traveled $100 \mathrm{~km}$ northeast in May 2005 (Fig. 2), along with approximately half of the herd, and returned in November 2005.
The same 4 deer made a similar migration the following year. We also observed an adult male mule deer move $35 \mathrm{~km}$ south in July 2004, then $35 \mathrm{~km}$ back north in November 2004, only to be harvested by a hunter near its initial point of capture. The 12 deer with the largest single movements between successive fixes in western Nebraska included 3 male and 2 female white-tailed deer, and 3 male and 4 female mule deer (Fig. 2). The movements were also omnidirectional and made by both yearling and adult deer. Female deer in both eastern and western Nebraska (173 and $459 \mathrm{~m}$, respectively) had larger average daily movements than males (166 and $427 \mathrm{~m}$ in eastern and western Nebraska, respectively, Table 3), but

Table 3

Average daily movement ${ }^{\mathrm{a}}$ (ADM) and average daily displacement ${ }^{\mathrm{b}}$ (ADD) in meters from point of capture for male and female white-tailed deer in eastern Nebraska and mule deer and white-tailed deer in western Nebraska, 2004-2006.

\begin{tabular}{lccccccc}
\hline & \multicolumn{2}{l}{ Eastern Nebraska } & & & \multicolumn{2}{l}{ Western Nebraska } & \\
\cline { 2 - 3 } \cline { 7 - 8 } & Male & Female & All Deer & & Male & Female & All Deer \\
\hline ADM & 166.4 & 173.0 & 171.1 & & 426.7 & 459.0 & 441.8 \\
ADD & 10.2 & 13.7 & 12.7 & & 26.5 & 28.3 & 27.4
\end{tabular}

a ADM-mean distance traveled between successive locations each day.

b ADD-mean distance from initial capture point each day. 


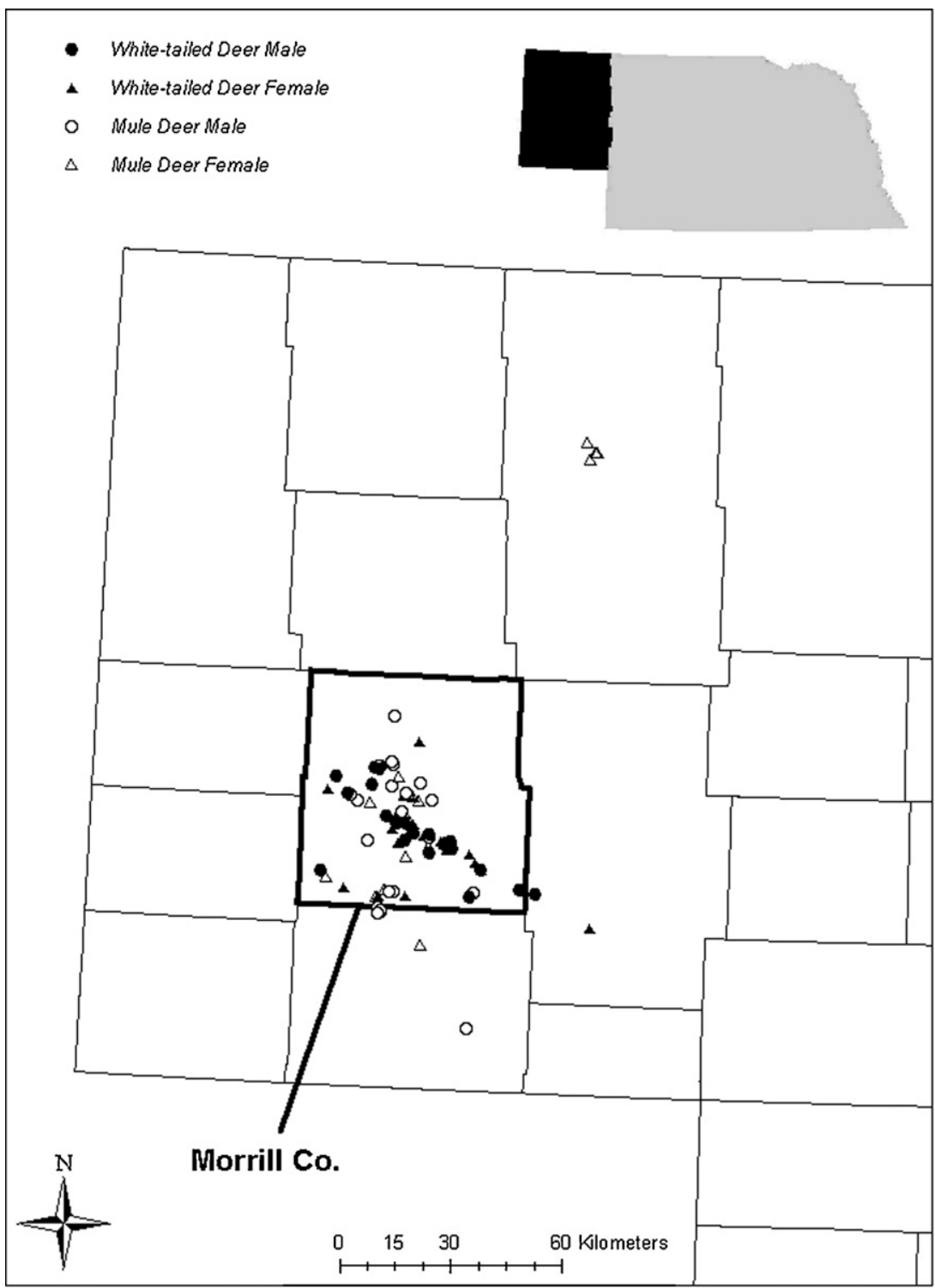

Fig. 2. Points of maximum displacement of individual deer by species and sex that were captured and radio-collared in Morrill County in western Nebraska, $2004-2006$.

again, the differences were not statistically significant $(p=0.533$ for deer in eastern and 0.397 for deer in western Nebraska). Deer in western Nebraska had much larger average daily movement and displacement than deer in eastern Nebraska (Table 3, Fig. 3). The proportion of movements that were $1-10 \mathrm{~km}$ was larger in western Nebraska (40\%) than eastern Nebraska (10\%, Fig. 3).

Table 4

Test statistic ( $D$, maximum distance between cumulative distribution function curves) for 6 models $^{\mathrm{a}}$ that simulated movement of deer in eastern and western Nebraska by rule set, 1991-2006.

\begin{tabular}{lll}
\hline Model & Eastern & Western \\
\hline DIST & 0.53 & 0.22 \\
CRW & 0.81 & 0.83 \\
FOCUS & 0.25 & 0.55 \\
SHIFT & 0.13 & 0.17 \\
MOVE & 0.12 & 0.14 \\
MOVEwEMI & 0.07 & 0.08 \\
\hline
\end{tabular}

a Models: Recreate distributions (DIST); correlated random walks (CRW); home point focus (FOCUS); Shifting home point (SHIFT); probabilistic movement (MOVE); probabilistic movement with emigration (MOVEwEMI).
We did not accurately recreate observed displacements by recreating observed distributions (DIST; $D=0.53,0.22$; Table 4). Correlated random walks (CRW) had the lowest fit of any rule set $(D=0.81,0.83)$. Movement with probabilistic turn angles around a home point (FOCUS) did not reproduce observed displacements $(D=0.25,0.55)$, but was improved by adding a shifting home point (SHIFT; $D=0.13,0.17$ ). Movement with probabilistic acceptance of displacement (MOVE, $D=0.12,0.14$ ) was an improvement over the FOCUS and SHIFT models. The addition of emigrators to MOVE model (MOVEwEMI) resulted in the best fit $(D=0.07,0.08$; Table 4).

Based on MOVEwEMI, best-fit values for optimal step size and maximum step for emigrators in eastern Nebraska (350 and $2800 \mathrm{~m}$, respectively) were less than in western Nebraska (370 and $2960 \mathrm{~m}$, respectively, Table 5). The values of $r$ (free probability parameter for acceptance of a proposed move) in eastern and western Nebraska (0.0058 and 0.0043 , respectively) showed that simulated deer in MC had movements that resulted in farther displacements than deer in DNWR. The proportion of simulated emigrators $(E)$ in western Nebraska was higher than in eastern Nebraska (0.13 and 0.10, respectively). 

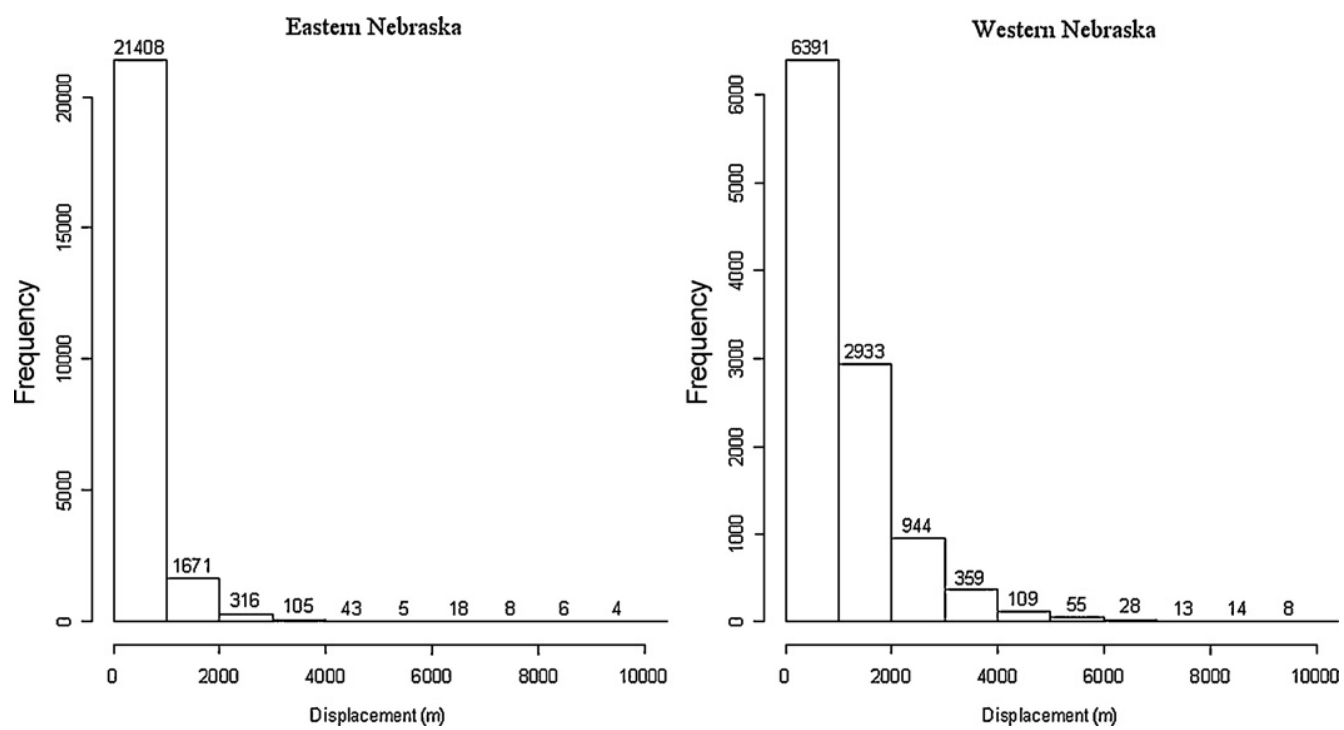

Fig. 3. Frequency of movements by white-tailed deer in eastern Nebraska, 1990-2006, and mule deer and white-tailed deer in western Nebraska, $2004-2006$.

We varied parameter values simultaneously in MOVEwEMI and scaled resulting mean displacements with empirical mean displacement (Tyre et al., 2006, 2007):

$\varphi=\frac{\bar{z}_{s}-\bar{z}_{e}}{\sigma_{e}}$
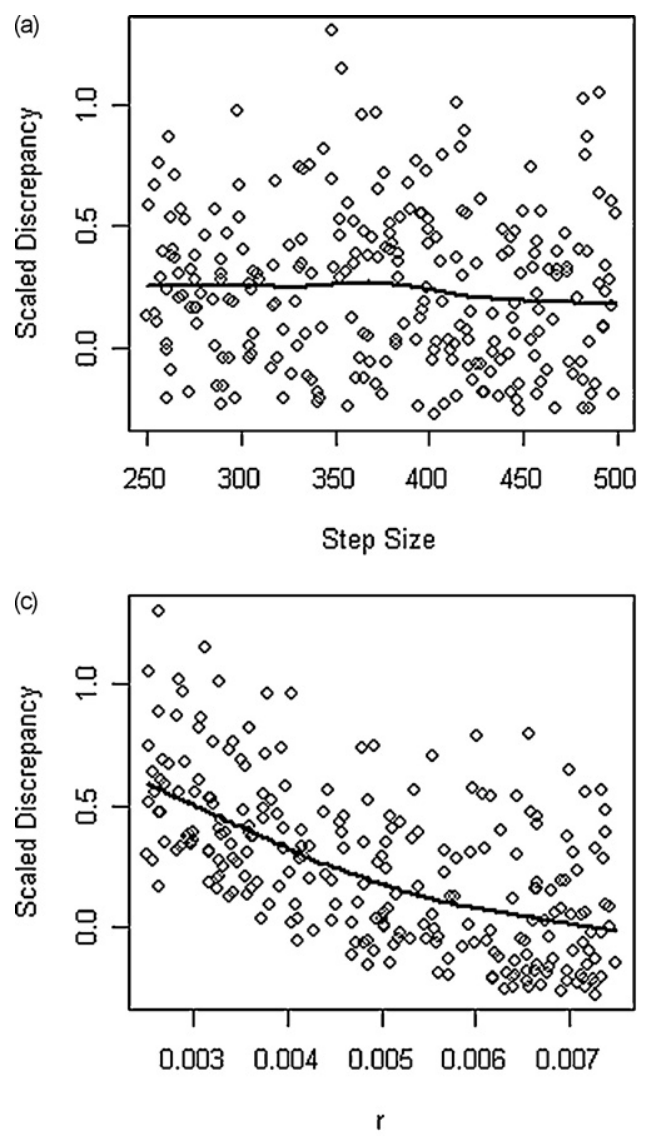

where $\varphi=$ scaled discrepancy, $\bar{z}_{s}=$ simulated mean displacement, $\bar{z}_{e}=$ empirical mean displacement, and $\sigma_{e}=$ standard deviation of empirical mean displacement.

We plotted the scaled discrepancies to determine the sensitivity of the simulation to changes in the 4 parameters (optimal step size, maximum step size, $r$, and proportion of emigrators). The erratic discrepancy plot for optimal step size (Fig. 4a) indicates no rela-
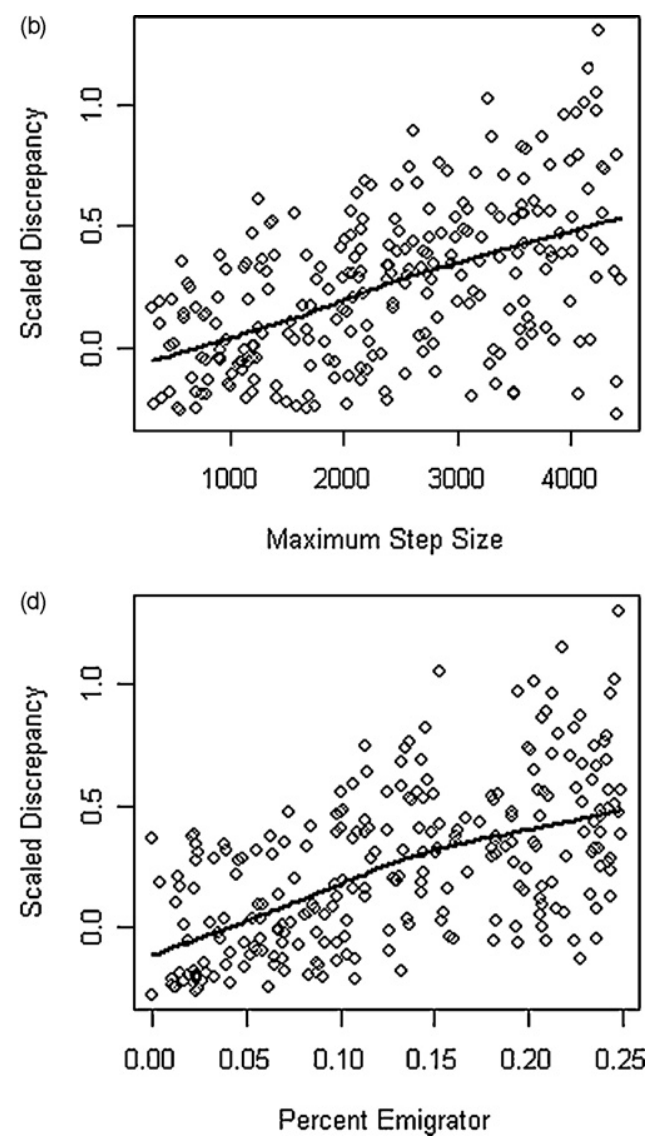

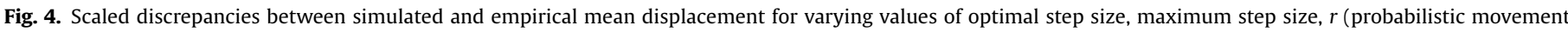

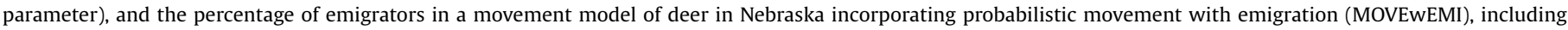
smoothed regression lines. 
Table 5

Optimal step size ${ }^{a}(l$, in $\mathrm{m})$, probability parameter $(r)$, proportion of emigrators $(E)$, and maximum step size ${ }^{\mathrm{b}}$ of emigrators $\left(l_{\max }\right.$, in $\left.\mathrm{m}\right)$ for best-fit runs of a model incorporating a probabilistic move with emigration (MOVEwEMI) for deer in eastern and western Nebraska, 1990-2006.

\begin{tabular}{lll}
\hline & Eastern & Western \\
\hline$l$ & 350 & 370 \\
$r$ & 0.0058 & 0.0043 \\
$E$ & 0.10 & 0.13 \\
$l_{\max }$ & 2800 & 2960 \\
\hline
\end{tabular}

a Optimal step size refers to the daily movement length for all deer excluding emigrators.

b Maximum step size refers to the maximum daily distance an emigrator can move with guaranteed acceptance.

tionship between step size and mean displacement over the range of simulated values and that displacement is driven by the variation in the other 3 parameters. The discrepancy plots for maximum step size (Fig. 4b) and percent emigrator (Fig. 4d) indicate that lower values of these parameters tend to lower discrepancies, and that the effect of low values of these parameters on mean displacement may override the variation in optimal step size and $r$. Maximum step size refers to the largest movement that an emigrator can make. Higher values of the proportion of emigrators tended to result in larger discrepancies, with the largest observed discrepancies corresponding to the highest values of both parameters and the smallest discrepancies corresponding to low values of the proportion of emigrators (Fig. 5). The grouping of points for values of $r$ (Fig. 4c) is static for the range of simulated values, which indicates that the effects of values of $r$ on mean displacement were relatively unaffected by the variation in the other 3 parameter values.

(a)
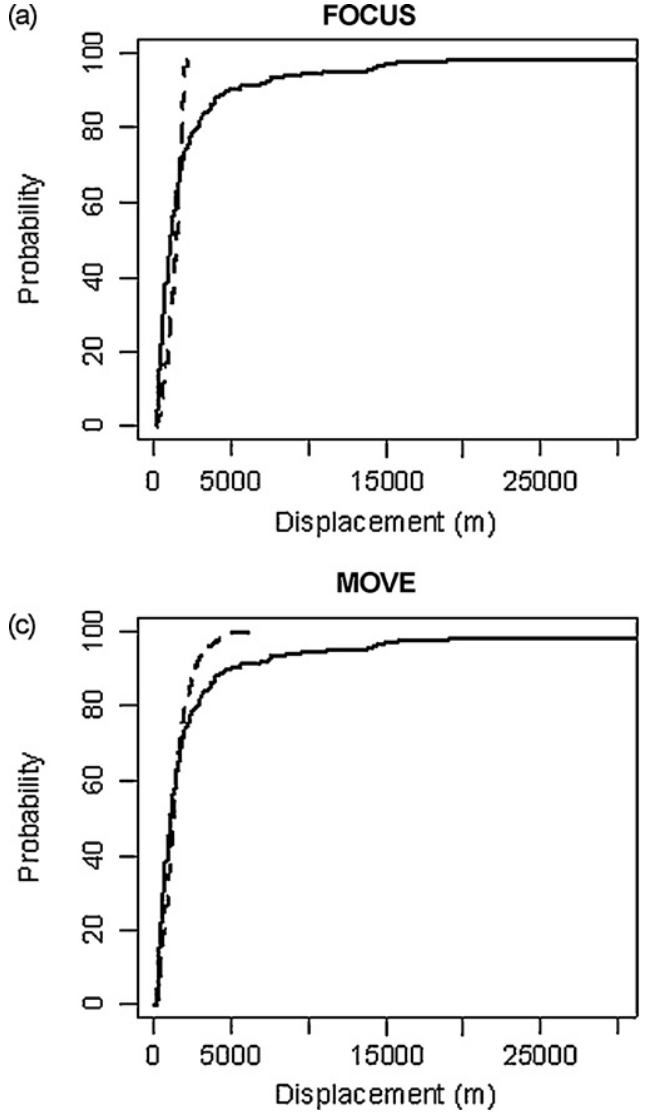

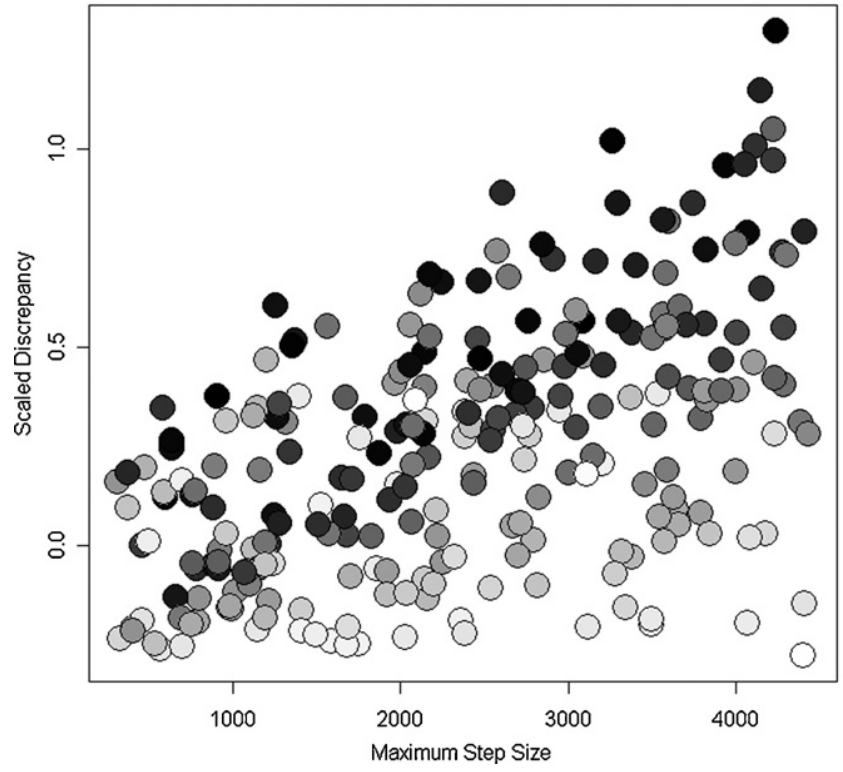

Fig. 5. Scaled discrepancy between simulated and empirical mean displacement for varying values of optimal step size, maximum step size, $r$ (probabilistic movement parameter), and the percentage of emigrators in a movement model of deer in Nebraska incorporating probabilistic movement with emigration (MOVEwEMI). Darker points correspond to higher values of the proportion of emigrators by simulation.

(b)
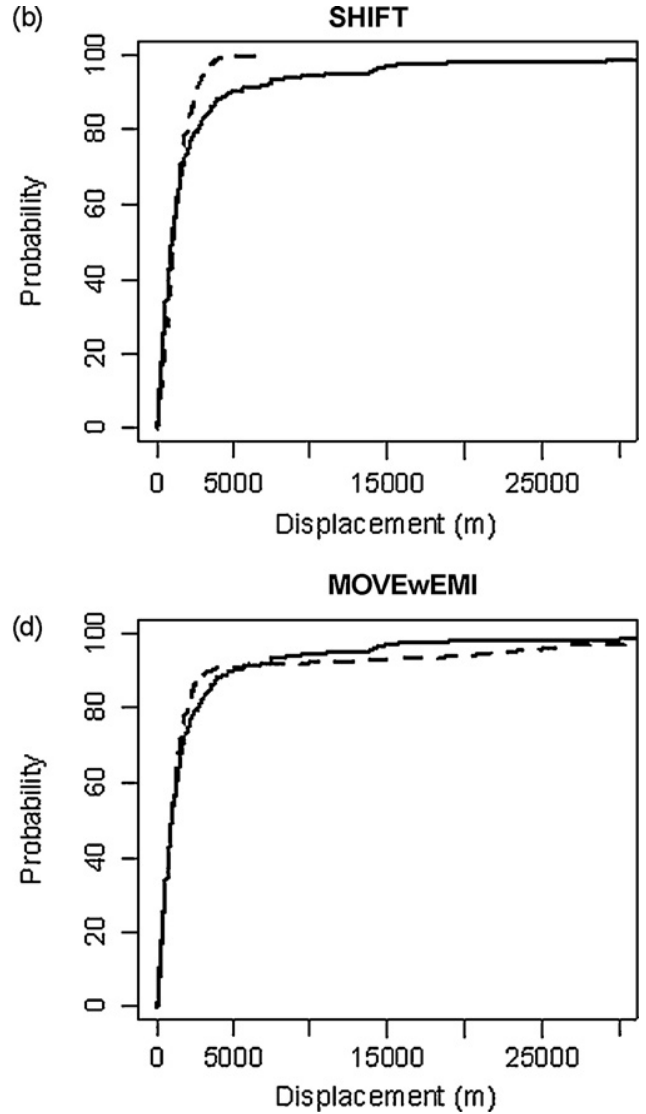

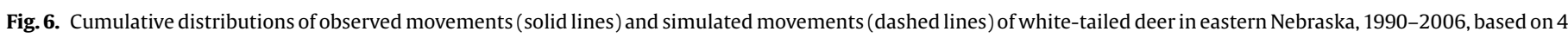

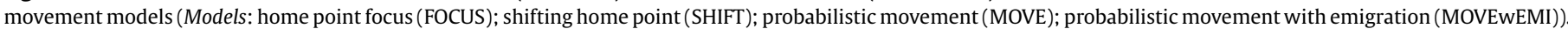


(a)

(a)
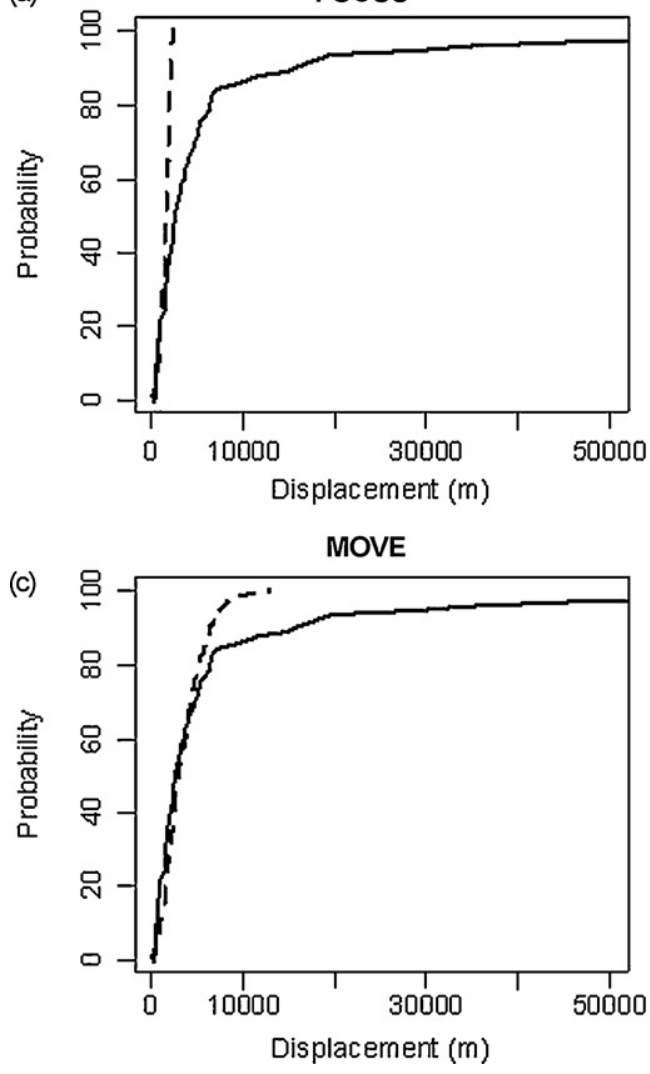

(b)
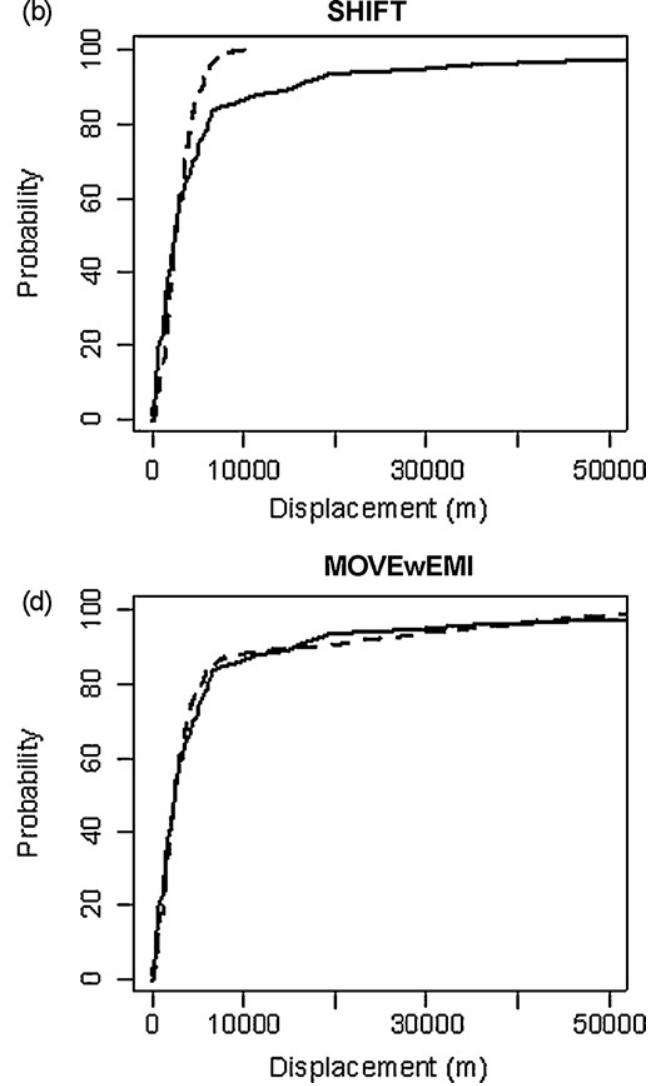

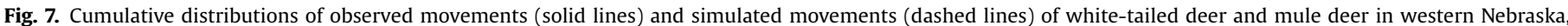

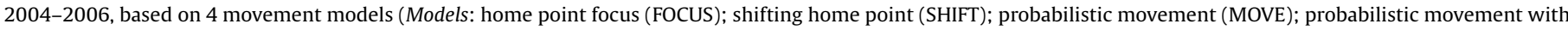
emigration (MOVEwEMI)).

\section{Discussion}

The absence of differences in movement by species, sex, and age is likely due to the large variation in individual movement characteristics. The observed migration distance of $100 \mathrm{~km}$ is similar to average migration distances of mule deer in Wyoming (Sawyer et al., 2005), Montana (Mackie et al., 1998), and Idaho (Thomas and Irby, 1990). We expected DIST and CRW to overestimate displacement because distinct home ranges have been observed for deer in Nebraska (VerCauteren, 1993, 1998; VerCauteren and Hygnstrom, 1998), and both models assume no spatial fidelity. Random walks in 2 dimensions assume no directional persistence (move direc- tion at time $t+1$ is not affected by that at time $t$; Pielou, 1977; Turchin, 1998), but this assumption rarely holds true in nature (Kareiva and Shigesada, 1983), especially for deer that migrate, disperse, or forage within a home range. Correlated random walks have recently been used to describe migration by caribou (Bergman et al., 2000), dispersal by wood frogs (Boone et al., 2006), and foraging by bottlenose dolphins (Bailey and Thompson, 2006), which are 3 movement behaviors commonly expressed by deer, making CRW a likely candidate. Correlated random walks assume directional persistence (Patlak, 1953; Turchin, 1998), measured by the average cosine of turn angles, but still include no component of fidelity to a home range.

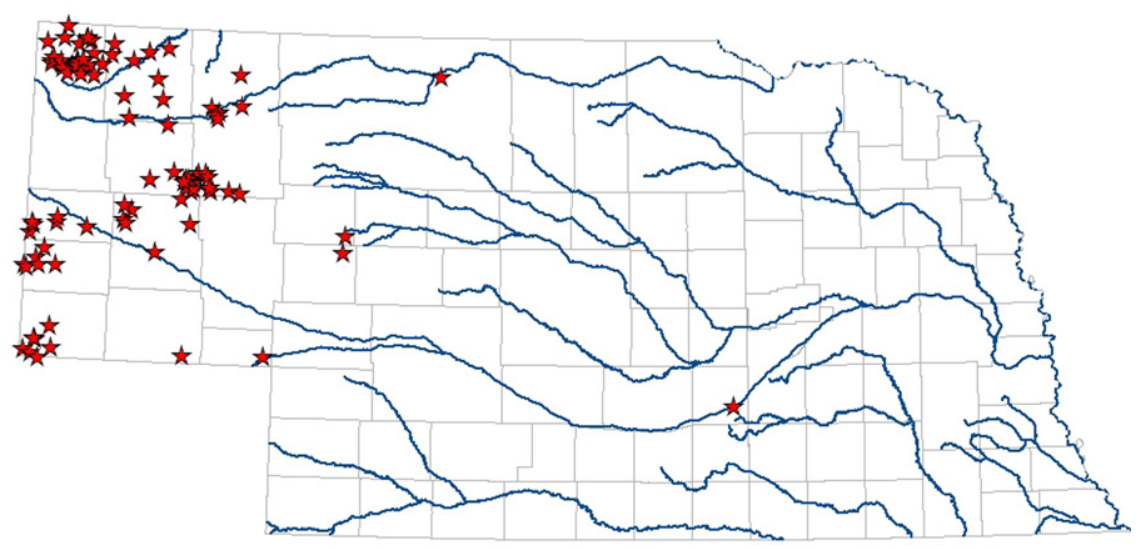

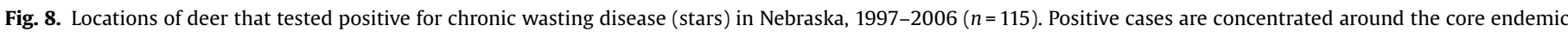
area of the disease, but individual cases have been observed progressively eastward (NGPC 2006). 
We attempted to correct the absence of spatial fidelity with FOCUS by making individuals turn, on average, toward their respective home points. Simulated displacements fit the lower $20 \%$ of observed displacements, but did not fit middle to large displacements well (Fig. 6a). We added random establishment of new home points in an attempt to recreate larger displacements with SHIFT, but movement driven by turn angles still underestimated observed distributions (Fig. 6b). We used MOVE in an attempt to allow deer to accept a series of moves that would lead to large displacements, but keep the majority of displacements small. The model MOVE appeared to simulate the correct proportion of the population making larger moves, but the resulting displacements were still too small (Fig. 6c). The addition of a small proportion (10-13\%) of emigrators considerably improved the fit of the models to empirical distributions (Fig. 6d). The same progression of relationships between observed and simulated movements developed for whitetailed deer and mule deer in western Nebraska (Fig. 7a-d). We believe the resulting fit of MOVEwEMI to the empirical distribution will be suitable to simulate movement of deer in an attempt to predict the potential for the spread of CWD in Nebraska.

Since 1997, 115 CWD-infected deer have been documented in the Panhandle of western Nebraska (NGPC, personal communication; Fig. 8). The North Platte River runs west-east across Nebraska. The potential for establishment of CWD in eastern Nebraska is assumed to be high if sympatric mule deer and white-tailed deer use the river valley as a travel corridor. Transmission of CWD occurs through feces, urine, blood, saliva, and residual environmental contamination (Williams et al., 2002; Mathiason et al., 2006). We observed a herd of about 50 mule deer (including 4 collared deer, Fig. 1) migrate approximately $100 \mathrm{~km}$ away from an area known to contain the disease and perpendicular to the river corridor for 6 months. If any of these deer were actively shedding CWD, they likely introduced the disease agent into previously uninfected areas. The spread of CWD in Nebraska may be driven by the highly variable movements made by a small proportion of deer. We observed large displacements (10-100 km, for dispersal, migration, and unknown reasons) that if made by an infected individual, would potentially establish the disease in a new area. Precise estimates of transmission rates, incubation times, and latency of CWD are unavailable, but transmission and potential for introduction due to environmental contamination are assumed to be high, given the observed movements of deer (Oyer et al., 2007). The appearance of cases outside of the Panhandle region of western Nebraska may illustrate the early stages of individual deer establishing CWD in previously naïve populations (Fig. 8).

The differences in the optimal parameters for MOVEwEMI (Table 5) are reasonable and indicative of the differences between the deer in eastern and western Nebraska. We expected parameter values to favor larger moves and resulting displacements for deer in western Nebraska over those in eastern Nebraska based on the empirical distribution of displacements (Fig. 3). Deer in DNWR have ample food, water, and cover available in relatively small heterogeneous patches of intermixed food an cover, while deer in western Nebraska travel longer distances between large homogenous blocks of cropland or pasture.

We used an individual-based model to account for potential differences in movement characteristics by different species, sex, and age classes of deer. Older males, and males in general, tend to carry CWD in higher prevalence than other sex-age classes of deer (Miller and Conner, 2005), and thus may be best modeled as individuals rather than part of a population. Our movement models will be used in conjunction with survival and epidemiological models to predict the spread of CWD in Nebraska. We will simulate the movement of deer concurrently with mortality and parturition over several generations to determine the probability of establishing CWD into previously unexposed populations across the state.
We will then use simulated transmission of CWD and thresholds of higher probabilities of potential occurrence based on repeated simulation of redistribution of the population based on MOVEwEMI to determine the risk of outbreak and significant mortality of deer in eastern Nebraska if the disease was carried there by dispersal of infected deer or transportation of an infected carcass by hunters. Results will be used to help determine sampling procedures for future surveillance and the potential for vaccination (Pilon et al., 2007). Culling has been proposed as a means to slow the spread of CWD, both by killing infected deer and by lowering densities of deer, which could lead to less dispersal (Williams et al., 2002). Our results indicate that selective culling of individuals that migrate or disperse may help slow the spread of the disease. Deer that migrate or disperse have the potential to spread CWD greater distances into areas that were previously uninfected.

\section{Acknowledgments}

We thank the landowners in Nebraska that allowed access for trapping and locating deer and all of the technicians that spent countless hours in the field. We thank George Gage, Larry Klimek, and the staff at DNWR for their support of our research over the years. We thank Kit Hams, Bruce Trindle, and the Nebraska Game and Parks Commission for providing access to data on CWD. Funding was provided by the USDA-APHIS-WS-National Wildlife Research Center, Nebraska Game and Parks Commission, USGSBiological Resources Division, Boone and Crockett Club, U.S. Fish and Wildlife Service, Cabelas, Inc., Nebraska Bowhunters Association, and the University of Nebraska-Lincoln.

\section{References}

Bailey, H., Thompson, P., 2006. Quantitative analysis of bottlenose dolphin movement patterns and their relationship with foraging. Journal of Applied Animal Ecology $75,456-465$.

Bergman, C., Schaefer, J., Luttich, S., 2000. Caribou movement as a correlated random walk. Oecologia 123, 364-374.

Boone, R.B., Johnson, C.M., Johnson, L.B., 2006. Simulating wood frog movement in central Minnesota, USA using a diffusion model. Ecological Modelling 198, $255-262$.

Brinkman, T.J., Deperno, C.S., Jenks, J.A., Haroldson, B.S., Osborn, R.G., 2005. Movement of female white-tailed deer; effects of climate and intensive row-crop agriculture. Journal of Wildlife Management 69, 1099-1111.

Gilsdorf, J.M., VerCauteren, K.C., Hygnstrom, S.E., Walter, W.D., Boner, J.R., Otto, R.E., Clements, G.M., 2008. An integrated vehicle-mounted very-high frequency telemetry system. Journal of Wildlife Management 72, 1241-1246.

Grimm, V., Railsback, S.F., 2005. Individual-based Modeling and Ecology. Princeton University Press, Princeton, NJ, USA.

Holzenbein, S., Marchinton, R.L., 1992. Spatial integration of maturing male white-tailed deer into the adult population. Journal of Mammalogy 73, 326334.

Kammermeyer, K.E., Marchinton, R.L., 1976. Notes on dispersal of male white-tailed deer. Journal of Mammalogy 57, 776-778.

Kareiva, P.M., Shigesada, N., 1983. Analyzing insect movement as a correlated random walk. Oecologia 56, 234-238.

Kenward, R.E., Walls, S.S., Hodder, K.H., 2001. Life path analysis: scaling indicates priming effects of social and habitat factors on dispersal distances. Journal of Animal Ecology 70, 1-13.

Kreeger, T.J., Montgomery, D.L., Jewell, J.E., Schultz, W., Williams, E.S., 2006. Oral transmission of chronic wasting disease in captive Shira's moose. Journal of Wildlife Diseases 42, 640-645.

Long, E.S., Diefenbach, D.R., Rosenberry, C.S., Wallingford, B.D., Grund, M.D., 2005. Forest cover influences dispersal distance of white-tailed deer. Journal of Mammalogy 86, 623-629.

Mackie, R.J., Pac, D.F., Hamlin, K.L., Dusek, G.L., 1998. Ecology and Management of Mule Deer and White-tailed Deer in Montana. Montana Fish, Wildlife, and Parks, Bozeman, MT, USA.

Mathiason, C.K., Powers, J.G., Dahmes, S.J., Osborn, D.A., Miller, K.V., Warren, R.J., Mason, G.L., Hays, S.A., Hayes-Klug, J., Seelig, D.M., Wild, M.A., Wolfe, L.L., Spraker, T.R., Miller, M.W., Sigurdson, C.J., Telling, G.C., Hoover, E.A., 2006. Infectious prions in the saliva and blood of deer with chronic wasting disease. Science 314, 133-135.

McKay, M.D., Beckman, R.J., Conover, W.J., 1979. A comparison of three methods for selecting values of input variables in the analysis of output from a computer code. Technometrics 21, 239-245. 
Miller, M.W., Conner, M.M., 2005. Epidemiology of chronic wasting disease in freeranging mule deer: spatial, temporal, and demographic influences on observed prevalence patterns. Journal of Wildlife Diseases 41, 275-290.

Miller, M.W., Williams, E.S., McCarty, C.W., Spracker, T.R., Kreeger, T.J., Larsen, C.T., Thorne, E.T., 2000. Epizootiology of chronic wasting disease in free-ranging cervids in Colorado and Wyoming. Journal of Wildlife Diseases 36, 676-690.

Nelson, M.E., 1998. Development of migratory behavior in northern white-tailed deer. Canadian Journal of Zoology 76, 426-432.

Nelson, M.E., Mech, L.D., Frame, P.F., 2004. Tracking of white-tailed deer migration by global positioning system. Journal of Mammalogy 85, 505-510.

Nixon, C.M., Mankin, P.C., Etter, D.R., Hansen, L.P., Brewer, P.A., Chelsvig, J.E., Esker T.L., Sullivan, J.B., 2007. White-tailed deer dispersal behavior in an agricultural environment. American Midland Naturalist 157, 212-220.

Oyer, A.M., Mathews, N.E., Skuldt, L.H., 2007. Long-distance movement of a whitetailed deer away from a chronic wasting disease area. Journal of Wildlife Management 71, 1635-1638.

Patlak, C.S., 1953. Random walk with persistence and external bias. Bulletin of Mathematical Biophysics 15, 311-338.

Pielou, E.C., 1977. Mathematical Ecology. John Wiley and Sons, New York, NY, USA.

Pilon, J., Loiacono, C., Okeson, D., Lund, S., Vercauteren, K., Rhyan, J., Miller, L., 2007. Anti-prion activity generated by a novel vaccine formulation. Neuroscience Letters $429,161-164$

R Development Core Team, 2005. R: A Language and Environment for Statistical Computing. R Foundation for Statistical Computing, Vienna, Austria. ISBN $3-$ 900051-07-0, URL http://www.R-project.org.

Rosenberry, C.S., Conner, M.C., Lancia, R.A., 2001. Behavior and dispersal of whitetailed deer during the breeding season. Canadian Journal of Zoology 79, 171-174.

Sawyer, H., Lindzey, F., McWhirter, D., 2005. Mule deer and pronghorn migration in western Wyoming. Wildlife Society Bulletin 33, 1266-1273.
Spraker, T.R., Miller, M.W., Williams, E.S., Getzy, D.M., Adrian, W.J., Schoonveld G.G., Spowart, R.A., O’Rourke, K.I., Miller, J.M., Merz, P.A., 1997. Spongiform encephalopathy in free-ranging mule deer (Odocoileus heminous), white-tailed deer (Odocoileus virginianus), and Rocky Mountain elk (Cervus elaphus nelsoni) in northcentral Colorado. Journal of Wildlife Diseases 33, 1-6.

Thomas, T., Irby, L., 1990. Habitat use and movement patterns by migrating mule deer in southeastern Idaho. Northwest Science 64, 19-27.

Turchin, P., 1998. Quantitative Analysis of Movement: Measuring and Modeling Population Redistribution in Animals and Plants. Sinauer Associates, Inc., Sunderland, MA, USA.

Tyre, A.J., Tenhumberg, B., Bull, C.M., 2006. Identifying landscape scale patterns from individual scale processes. Ecological Modelling 199, 442-450.

Tyre, A.J., Kerr, G.D., Tenhumberg, B., Bull, C.M., 2007. Identifying mechanistic models of spatial behaviour using pattern-based modeling: an example from lizard home ranges. Ecological Modelling 208, 307-316.

U.S. Census Bureau, 2000. www.census.gov, accessed 1 November 2006.

VerCauteren, K.C., 1993. Home range and movement characteristics of female whitetailed deer at DeSoto National Wildlife Refuge. MS Thesis. University of Nebraska, Lincoln, USA.

VerCauteren, K.C., 1998. Dispersal, home range fidelity, and vulnerability of whitetailed deer in the Missouri River Valley. PhD Dissertation. University of Nebraska, Lincoln, USA.

VerCauteren, K.C., Hygnstrom, S.E., 1998. Effects of agricultural activities and hunting on home ranges of female white-tailed deer. Journal of Wildlife Management 62 280-285.

Williams, E.W., Miller, M.W., Kreeger, T.J., Kahn, R.H., Thorne, E.T., 2002. Chronic wasting disease of deer and elk: a review with recommendations for management Journal of Wildlife Management 66, 5-15. 